\title{
ANALISIS POTENSI NUART SCULPTURE PARK SEBAGAI DAYA TARIK WISATA BUDAYA UNGGULAN DI KOTA BANDUNG
}

\author{
Meiliana Gildauli ${ }^{1}$ \\ Jurusan Administrasi Niaga \\ DIII-Usaha Perjalanan Wisata, Politeknik Negeri Bandung \\ Email:meilianagildauli@gmail.com.com \\ Deddy Sobarna Sutaji ${ }^{2}$ \\ DIII-Usaha Perjalanan Wisata, Politeknik Negeri Bandung \\ Email:deddysobarna@gmail.com.com
}

\begin{abstract}
ABSTRAK
Bandung merupakan kota kreatif yang banyak menampung seniman dengan hasil karya menarik, beberapa diantaranya mendirikan sebuah ruang publik menjadi tujuan wisata bagi wisatawan, salah satunya yaitu NuArt Sculpture Park yang merupakan taman patung terbesar di Indonesia. Penelitian ini bertujuan untuk menggambarkan potensi dan daya tarik wisata di NuArt Sculpture Park dan menentukan bagaimana upaya yang dapat dilakukan untuk menjadikan NuArt sebagai daya tarik wisata budaya unggulan di Kota Bandung. Penelitian ini dilakukan dengan menggunakan metode kualitatif dimana teknik pengumpulan data dengan cara observasi, wawancara, dan studi dokumentasi. Hasil penelitian dianalisis dengan metode deskriptif dan analisis SWOT. Hasil dari penelitian untuk daya tarik NuArt Sculpture Park dapat dilihat dari atraksi, aksesibilitas, amenitas, masyarakat, dan aktivitas yang seluruhnya sudah dimiliki NuArt Sculpture Park, namun saat ini NuArt belum menjadi daya tarik wisata budaya unggulan di Kota Bandung, oleh karena itu perlu strategi yang dilakukan berdasarkan analisis SWOT seperti meningkatkan fasilitas dan layanan, merancang acara rutin, melakukan promosi lebih gencar, dan kerja sama dengan pemerintah Kota Bandung.
\end{abstract}

Kata kunci: Potensi, daya tarik wisata, dan budaya

\section{ANALYSIS OF THE POTENTIAL NUART SCULPTURE PARK AS A LEADING CULTURAL TOURISM ATTRACTION IN BANDUNG}

\begin{abstract}
Bandung is a creative city which has many interesting artists to work, some of them set up a public space into a destination for tourists, one of which is NuArt Sculpture Park which is the largest sculpture park in Indonesia. This study aims to illustrate the potential and attractions in NuArt Sculpture Park and determine
\end{abstract}


how efforts should be made to make NuArt as a cultural tourist attraction featured in Bandung. This research was conducted using qualitative methods in which data collection techniques by observation, interviews, and documentation. The results were analyzed with descriptive methods and SWOT analysis. The results of the research can be seen from the attractions, accessibility, amenitas, communities, and activities which are all owned NuArt Sculpture Park, but this time NuArt not become a cultural tourist attraction featured in Bandung, therefore it needs a strategy which is based on SWOT analysis as improving facilities and services, designing a routine event, promoting and cooperate wih the government of Bandung.

Keywords: Potention, attraction and culture.

\section{PENDAHULUAN}

Dinas Kebudayaan dan Pariwisata (2015) menetapkan potensi objek dan daya tarik wisata unggulan di Kota Bandung diantaranya adalah berupa Museum seperti Geologi, Siliwangi, Sri Baduga, Asia Afrika, Pos Indonesia, dan Yayasan. Hal ini dapat disebabkan karena letaknya yang strategis dekat dengan pusat kota. Namun, selain museum sebenarnya masih banyak lagi potensi daya tarik wisata di Kota Bandung yang menarik untuk dikunjungi.

Bandung menyandang julukan kota kreatif, karena Kota Bandung merupakan tempat berkembangnya seni rupa modern sehingga banyak komunitas dan pelaku kreatif seni. Hal ini menjadi daya tarik wisata di Kota Bandung, banyak seniman di Bandung yang mendirikan galeri untuk dijadikan destinasi wisata yang layak dikunjungi wisatawan sehingga mampu memberikan edukasi di bidang seni. Dari beberapa galeri seni yang ada di kota Bandung, masing-masing memiliki daya tarik dan keunikan tersendiri. Salah satu galeri seni yang menarik untuk dikunjungi adalah NuArt Sculpture Park atau lebih dikenal dengan sebutan NuArt.

NuArt merupakan Sculpture Park atau taman patung pahat terbesar di Indonesia yang didirikan oleh seniman terkenal asal Bali, Nyoman Nuarta., lokasinya berada di Jl. Setraduta Raya L-6 Sarijadi, Bandung. NuArt memiliki fasilitas wisata yang lengkap antara lain galeri seni, taman patung, gedung audiovisual, gedung pertemuan, cafe, coffee shop, tempat parkir, toilet dan musholla. Selain fasilitas yang lengkap NuArt memiliki keunikan berbeda dengan daya tarik wisata lain di Kota Bandung, seperti koleksi berupa patung yang memiliki nilai seni tinggi serta arsitektur bangunan yang menarik. Namun, menurut Raisa selaku manajemen NuArt rata-rata jumlah kunjungan wisatawan pertahun adalah sekitar 12.000 orang. Jumlah tersebut masih rendah jika dibandingkan dengan jumlah kunjungan pada daya tarik wisata lain yang ada di Kota Bandung. Selain itu petunjuk lokasi NuArt di jalan raya umum masih belum terlihat dan lokasi NuArt berada di dalam perumahan sehingga sulit dijangkau karena tidak terdapat transportasi umum. 
Saat ini NuArt belum termasuk dalam objek dan daya tarik wisata unggulan Kota Bandung, oleh karena itu perlu adanya analisis untuk menggambar-kan daya tarik wisata di NuArt serta upaya yang dapat dilakukan untuk menjadikan NuArt sebagai daya tarik wisata budaya unggulan di Kota Bandung. Adapun tujuan dari penelitian ini untuk mengetahui gambaran ptensi dan daya tarik wisata di NuArt Sculpture Park dan menggambarkan upaya apa yan dapat dilakukan NuArt Sculpture Park sebagai daya tarik wisata unggulan di kota Bandung.

\section{LANDASAN TEORI}

\section{Daya Tarik Wisata}

Daya tarik wisata merupakan potensi yang menjadi pendorong kehadiran wisatawan ke suatu daerah tujuan wisata. Daya tarik wisata harus dirancang dan dibangun atau dikelola secara profesional sehingga dapat menarik wisatawan untuk datang (Suwantoro, 2004). Dalam UU No. 10 Tahun 2009 tentang kepariwisataan, daya tarik wisata adalah segala sesuatu yang memiliki keunikan, keindahan dan nilai yang berupa keanekaragaman kekayaan alam, budaya, dan hasil buatan manusia yang menjadi sasaran atau tujuan kunjungan wisatawan. Daya tarik wisata itu harus dikelola sedemikian rupa agar keberlangsungannya dan kesinambungan-nya terjamin. Sedangkan daya tarik wisata budaya menurut Ismayanti (2010) merupakan daya tarik wisata yang memanfaatkan memanfaatkan budaya sebagai potensi wisata seperti situs arkeologi, pola kehidupan atau adat istiadat masyarakat, festival budaya, seni dan kerajinan.

\section{Daya Tarik Wisata Unggulan}

Menurut Kamus Besar Bahasa Indonesia, kata unggul memiliki arti lebih tinggi daripada yang lain, terbaik, dan terutama. Dinas Pariwisata dan Kebudayaan (DISPARBUD) Jawa Barat menjelaskan daya tarik wisata unggulan merupakan daya tarik yang memiliki kriteria tertentu yang barasal dari konsep RIPARPROV (Rencana Induk Pem-bangunan Kepariwisataan Provinsi) Jawa Barat no. 15 Tahun 20an15-2025. Maksud RIPARPROV adalah sebagai pedoman dalam penyelenggaraan pembangunan kepariwisataan Daerah Provinsi yang terencana, terpadu, dan berkesinambung-an. Dari pedoman tersebut dirumuskan kriteria daya tarik wisata unggulan sebagai berikut:

1. Atraksi merupakan unsur yang menarik wisatawan untuk datang ke destinasi

2. Aksesibilitas yaitu kemudahan bagi wisatawan untuk mencapai tujuan

3. Amenitas merupakan hal yang dapat memenuhi kebutuhan wisatawan selama berada di destinasi, terdiri dari fasilitas umum dan fasilitas pariwisata.

4. Masyarakat di sekitar daya tarik wisata yang menjadi hal penting bagi wisatawan selama berada di destinasi karena mereka perlu merasa nyaman dan merasa berkesan, hal ini didasarkan pada konsep sapta pesona yaitu aman, tertib, bersih, sejuk, indah, ramah dan kenangan.

5. Aktivitas merupakan kegiatan yang dapat dilakukan wisatawan selama berada di sekitar objek yang menjadi daya tarik wisata seperti berfoto, berenang dan sebagainya. 


\section{METODE PENELITIAN}

Metode yang digunakan dalam penelitian ini, adalah penelitian kualitatif. Menurut Maleong (2012), penelitian kualitatif merupakan penelitian yang bertujuan untuk memahami fenomena yang dialami oleh subjek penelitian seperti perilaku, persepsi, motivasi, tindakan, atau yang lainnya secara holistik, dan dengan cara deskripsi dalam bentuk kata-kata, gambar dan bukan angka-angka pada suatu konteks khusus yang alamiah. Teknik pengumpulan data dilakukan dengan cara observasi, wawancara, dan studi dokumentasi.

\section{Analisis Deskriptif}

Menurut Creswell dalam Sangadji dan Sopiah (2010) penelitian deskriptif adalah metode penelitian yang berusaha menggambarkan dan menginterpretasikan objek apa adanya. Tujuannya untuk menggambarkan secara sistematis fakta, objek, atau subjek yang diteliti apa adanya secara tepat.

\section{Analisis SWOT}

SWOT merupakan kepanjangan dari strength (kekuatan), opportunity (peluang), weakness (kelemahan) dan threat (ancaman). Analisis SWOT membanding-kan antara faktor eksternal berupa peluang dan ancaman dengan faktor internal berupa kekuatan dan kelemahan sehingga dari hasil analisis dapat diambil suatu keputusan strategis bagi perusahaan (Utama dan Mahadewi, 2012).

\section{a. Menyusun dan menentukan faktor-faktor strategis Eksternal dan Internal suatu perusahaan.}

Menyusun dan menghitung nilai bobot, rating, dan skor untuk tabel eksternal dan internal dibuat dengan teknik skala menurut Fahmi (2014), adalah sebagai berikut:

1. Bobot nilai

$1,00=$ sangat penting

$0,75=$ penting

$0,50=$ standar

$0,25=$ tidak penting

$0,10=$ sangat tidak penting

2. Rating nilai

5 = sangat baik

$4=$ baik

$3=$ netral

2 = tidak baik

$1=$ sangat tidak baik

3. Skor nilai

untuk skor nilai dihitung dengan mempergunakan formula sebagai berikut:

$$
\mathrm{SN}=\mathrm{BN} \times \mathrm{RN}
$$


Keterangan:

$\mathrm{SN}=$ Skor nilai

$\mathrm{BN}=$ Bobot Nilai

$\mathrm{RN}=$ Rating Nilai

b. Menganalisis dan menentukan keputusan strategis dengan pendekatan Matriks SWOT

\section{Tabel 3.1 Tabel Matrik Analisis SWOT}

\begin{tabular}{|l|l|l|}
\hline & $\begin{array}{l}\text { Strenghts (S) } \\
\text { Daftar semua kekuatan } \\
\text { yanng dimiliki }\end{array}$ & $\begin{array}{l}\text { Weaknesses (W) } \\
\text { Daftar semua kelemahan } \\
\text { yang dimiliki }\end{array}$ \\
\hline $\begin{array}{l}\text { Opportunities (O) } \\
\text { Daftar semua peluang } \\
\text { yang dapat } \\
\text { Diidentifikasi }\end{array}$ & $\begin{array}{l}\text { Strategi SO } \\
\text { Gunakan semua kekuatan } \\
\text { yang dimiliki untuk } \\
\text { memanfaatkan peluang } \\
\text { yang ada }\end{array}$ & $\begin{array}{l}\text { Strategi WO } \\
\text { Atasi semua kelemahan } \\
\text { dengan memanfaatkan } \\
\text { semua peluang yang ada }\end{array}$ \\
\hline $\begin{array}{l}\text { Threats (T) } \\
\text { Daftar semua } \\
\text { ancaman yang dapat } \\
\text { Diidentifikasi }\end{array}$ & $\begin{array}{l}\text { Strategi ST } \\
\text { Gunakan semua kekuatan }\end{array}$ & $\begin{array}{l}\text { Strategi WT } \\
\text { Tekan semua kelemahan } \\
\text { dan cegah semua ancaman }\end{array}$ \\
\hline
\end{tabular}

\section{HASIL DAN PEMBAHASAN}

\section{A. Gambaran Potensi dan Daya Tarik Wisata NuArt Sculpture Park}

Dari hasil penelitian yang telah dilakukan, potensi dan daya tarik NuArt Sculpture Park terdiri dari:

\section{Atraksi}

a. Koleksi NuArt Sculpture Park

NuArt Sculpture Park memiliki koleksi berupa patung yang hingga kini jumlahnya mencapai 300 buah. Koleksi patung di NuArt merupakan hasil karya seniman Nyoman Nuarta dari sejak awal berkarir hingga karya terbaru. Koleksi patung ini menjadi daya tarik karena bentuknya yang unik dan abstrak serta mengandung makna yang berarti. Bahan utama pembuatan patung-patung Nyoman Nuarta rata-rata berasal dari tembaga, kuningan, besi dan poliester.

\section{b. Event NuArt Sculpture Park}

Terdapat event menarik yang diadakan di NuArt untuk menambah daya tarik wisata seperti pameran lukisan di dalam galeri seni, pentas tari, acara kreativitas untuk anak, penampilan band indie, dan pertunjukan teater. Namun event tersebut hanya diselenggarakan di waktu tertentu saja karena belum terdapat event rutin yang diselenggarakan di NuArt. 


\section{Aksesibilitas}

a. Kondisi jalan raya menuju NuArt Sculpture Park sangat baik dan dapat dijangkau oleh kendaraan kecil hingga bis ukuran besar. Terdapat pepohonan yang berada di sepanjang jalan ketika memasuki komplek perumahan Setraduta sehingga menambah pemandangan dan memberikan kesan sejuk kepada wisatawan selama perjalanan menuju lokasi NuArt Sculpture Park.

b. Tidak tersedia transportasi seperti angkutan umum yang melintasi lokasi wisata NuArt Sculpture Park, sehingga wisatawan yang tidak menggunakan kendaraan pribadi akan mengalami kesulitan untuk menuju ke lokasi.

c. Jika wisatawan memasuki perumahan Setraduta Raya, wisatawan dapat melihat papan petunjuk NuArt yang berada di depan jalan menuju gerbang NuArt Sculpture Park.

\section{Amenitas}

a. Fasilitas Umum

Fasilitas umum seperti Bank dan ATM yang berada di sekitar lokasi dapat dijangkau di wilayah sarijadi dan SPBU terdekat berada di Jl. Surya Sumantri.

b. Fasilitas Pariwisata

\section{Galeri}

digunakan untuk memamerkan koleksi hasil karya seni, galeri ini dirancang dengan gaya modern dan artistik. Bagian depan bangunan didesain dengan bahan transparan untuk memberikan pencahayaan yang baik agar mengurangi penggunaan listrik.

Wisatawan dapat menikmati setiap koleksi yang dipamerkan di dalam galeri seni. Selain koleksi patung, di dalam galeri juga terdapat fasilitas yang disediakan bagi wisatawan. Galeri ini terbagi dalam tiga lantai:

1.1 Lantai dasar terdiri dari ruang utama tempat menyimpan karya ukuran besar, toko souvenir, ruang VIP, ruangan Ibu menyusui, dan toilet.

1.2 Lantai 1 terdiri dari galeri A dan B, coffee shop, dan teras rupa

1.3 Lantai 2 merupakan galeri yang digunakan untuk kegiatan pameran yang bersifat temporer, dan ruang ini disewakan untuk seniman lain.

1.4 Lantai 3 terdiri dari ruang audio visual dan kantor

\section{Taman Patung}

Taman patung merupakan area terbuka yang menampilkan beberapa hasil karya patung berukuran besar. Tata letak patung tersebar secara acak di seluruh area taman dengan latar belakang pepohonan dan tanaman hias sehingga memberikan pemandangan yang berkesan bagi wisatawan. Selain itu juga terdapat air mancur yang menambah keindahan taman, area ini juga merupakan auditorium terbuka yang biasa digunakan untuk acara outdoor dan memiliki kapasitas hingga 1500 orang. 


\section{Workshop}

Workshop Merupakan area yang digunakan sebagai bengkel untuk pembuatan patung yang menjadi proyek karya NuArt seperti yang sedang dikerjakan saat ini adalah proyek penyelesaian patung Garuda Wisnu Kencana yang nantinya akan dikirim ke Bali. Lokasi workshop berada di paling bawah kawasan NuArt dekat dengan sungai. Wisatawan dapat melihat proses pembuatan karya-karya patung dari luar area workshop didampingi oleh guide karena area ini cukup berbahaya karena pekerjaan yang dilakukan di area workshop menggunakan alat berat dan bahan-bahan kimia sehingga tidak dapat dimasuki secara sembarangan.

\section{Gedung Kuning}

Gedung kuning merupakan gedung serba guna yang digunakan sebagai ruang pertemuan untuk mengadakan diskusi, presentasi seni dan kegiatan lain yang dapat dilakukan di dalam ruangan. Gedung ini disebut gedung kuning karena bangunan ini didominasi oleh warna kuning muda.

\section{Restoran dan Coffee Shop}

NuArt Sculpture Park menyediakan restoran dan coffee shop bagi wisatawan yang ingin bersantai di kawasan NuArt sambil menikmati makanan. Tersedia N Cafe yang menyediakan makanan khas bali seperti Balinese Bebek Crispy dan nasi campur. N Cafe terletak dibelakang galeri. Selain itu terdapat Copper and Brass yang merupakan coffee shop bagi wisatawan yang ingin sekedar duduk santai sambil menikmati minuman dan makanan ringan. Copper and Brass terletak di lantai 1 dalam galeri. Kondisi restoran dan coffee shop dalam keadaan baik dan terawat.

\section{Lahan Parkir}

Bagi wisatawan yang membawa kendaraan, NuArt Sculpture Park menyediakan lahan parkir yang cukup luas, dan dapat menampung kendaraan berukuran kecil hingga besar.

\section{Toilet dan Musholla}

NuArt Sculpture Park menyediakan toilet bagi wisatawan, kondisi toilet bersih dan terawat. Toilet yang tersedia berada di area dekat lahan parkir, dan keadaannya terpisah antara toilet laki-laki dan perempuan. Selain itu di dalam galeri juga disediakan toilet tepatnya di lantai dasar dan lantai dua. NuArt juga menyediakan ruang untuk beribadah yaitu musholla yang tersedia di samping lahan parkir.

\section{Ruang Audio-Visual}

Ruangan ini merupakan fasilitas dari NuArt yang dapat digunakan untuk kegiatan pemutaran film pendek bertema sosial maupun film dokumenter. Setelah proses renovasi ruangan ini melakukan re-launching pada tanggal 18 Juni 2016, ruangan ini memiliki kapasitas 100 orang. 


\section{Toko Souvenir}

Wisatawan yang ingin membeli cinderamata sebagai buah tangan dapat mengunjungi NuArt Craft Boutique yang menjual miniatur karya-karya patung Nyoman Nuarta, serta karya patung lainnya dari seniman maupun pengrajin lokal dan internasional. Namun saat penulis melakukan observasi, toko sedang mengalami renovasi sehingga berhenti beroperasi dan akan dibuka kembali setelah proses renovasi selesai. Nantinya selain menjual miniatur patung akan ada toko buku yang menjual karya tulis mengenai seni dan lain sebagainya.

10. Penginapan

Rencananya NuArt akan membangun penginapan sebagai tempat peristirahatan bagi wisatawan yang ingin bermalam di dalam kawasan NuArt Sculpture park, saat ini proyeknya masih dalam perencanaan dengan nama NuArt Boutique Cottage.

\section{Masyarakat}

Masyarakat di kawasan wisata ataupun petugas yang berada di destinasi yang berperan sebagai tuan rumah dengan mewujudkan konsep sadar wisata yang meliputi unsur-unsur aman, tertib, bersih, sejuk, indah, ramah, dan kenangan. Hal ini diperlukan untuk memberikan kenyaman-an bagi wisatawan dan meningkatkan kesejahteraan bagi seluruh masyarakat di destinasi wisata.

a. Keamanan

NuArt dilengkapi dengan pos keamanan serta penjaga keamanan tepatnya di dekat pintu gerbang kedatangan dan di area workshop yang selalu siaga mengawasi di sekitar kawasan sehingga wisatawan dapat merasa aman.

b. Ketertiban

Setiap wisatawan yang memasuki area NuArt Sculpture park diwajibkan untuk mengikuti aturan atau etika yang berlaku, hal ini diperlukan agar karya seni di dalam galeri tetap utuh dan terjaga. Adapun Etika di dalam galeri antara lain:

1. Dilarang menyentuh, bersandar, atau duduk di karya seni

2. Dilarang mengambil foto atau video

3. Dilarang makan atau minum di dalam galeri

4. Dilarang merokok

5. Dilarang berlari-lari atau bermain di dalam galeri

6. Harap menjaga ketenangan

7. Anak usia dibawah 12 tahun wajib didampingi orang dewasa

8. Dilarang membawa tas berukuran besar ke dalam galeri 


\section{c. Kebersihan}

Dari hasil pengamatan di lapangan, NuArt memiliki kondisi lingkungan yang bersih juga udara segar yang jauh dari polusi. Untuk tetap menjaga kebersihan, di sekitar halaman NuArt disediakan tempat sampah. Tersedia sekitar delapan tempat sampah di area taman NuArt dan di dalam galeri tersedia sekitar 4 tempat sampah.

d. Kesejukan

Saat memasuki area NuArt wisatawan akan melihat pepohonan yang mengelilingi kawasan. Pemilik NuArt berpegang teguh terhadap prinsip ramah lingkungan, sehingga dalam pengelolaannya dilakukan penanaman pohonpohon keras, seperti cemara, karet, dan ketapang sehingga menambah kesejukan.

e. Keindahan

Selain pepohonan, halaman NuArt juga ditumbuhi oleh bunga-bunga yang menambah keindahan dalam tatanan yang estetik dan bersifat alami, hal ini dapat menciptakan lingkungan dengan suasana yang indah sehingga memberikan kesan mendalam kepada wisatawan.

f. Keramahan

Saat memasuki kawasan NuArt wisatawan akan disambut oleh petugas keamanan serta guide yang yang bertugas di area NuArt. Para petugas bersikap ramah dan menyambut wisatawan dengan baik sehingga menambah kenyamanan wisatawan selama berada di lokasi.

\section{g. Kenangan}

Wisatawan yang berkunjung ke NuArt dapat mendatangi Craft Boutique untuk membeli cinderamata dari NuArt, selain itu juga bagi wisatawan yang mengikuti kegiatan short course yaitu pembuatan patung dari tanah liat, hasil karya yang dibuat wisatawan dapat dibawa pulang sehingga menjadi kenangan bagi wisatawan itu sendiri.

\section{Aktivitas}

Adapun aktivitas yang dapat dilakukan wisatawan selama berkunjung di

NuArt Sculpture Park adalah sebagai berikut:

a. Tour de Venue

Tour de Venue adalah kegiatan wisatawan dipandu oleh guide untuk mengelilingi kawasan NuArt mulai dari galeri, taman patung dan area workshop sambil mengenal konsep dan karya karya seni patung Nyoman Nuarta.

\section{b. Art Performance}

Merupakan kegiatan non-rutin yang diselenggarakan di kawasan NuArt. Wisatawan dapat menyaksikan kegiatan art performance yang dibawakan oleh artis dan para seniman, bentuknya bisa berupa tarian, musik, teater, pembacaan puisi, sajak, dan kegiatan seni lainnya. Rencananya art performance akan dijadikan sebagai agenda rutin NuArt. 


\section{c. Craft Corner}

Merupakan kegiatan yang dikhususkan untuk anak-anak. Adapun jenis kegiatan yang dilakukan antara lain membuat karya dari clay atau malam, menghias topeng, melukis, membuat kerajinan dari kertas, dan mewarnai, kegiatan untuk anak ini dilakukan di N Cafe. Craft Corner merupakan bagian dari program kegiatan di NuArt untuk memberikan edukasi dan melatih kreatifitas bagi anak dalam bidang seni sehingga mereka dapat berkreasi dan bereksplorasi dengan menghasilkan karya sendiri.

d. Visitor Short Course

Visitor short course adalah salah satu bentuk program berupa bimbingan juga pelatihan dalam bidang kesenirupaan dan desain seperti membuat patung dari tanah liat. Kegiatan ini disediakan untuk semua kalangan mulai dari turis asing, orangtua, remaja, dan anak-anak. Kegiatan ini hanya dapat dilaksanakan apabila telah melakukan pemesanan terlebih dahulu melalui manajemen NuArt.

e. Kegiatan Pameran Temporer

Kegiatan pameran temporer adalah kegiatan yang diselenggarakan pada waktu-waktu tertentu bentuknya berupa pameran lukisan. NuArt akan mendatangkan artis seniman atau desainer lokal yang telah terseleksi secara khusus.

f. Pemutaran slide atau film

Pemutaran slide atau film merupakan kegiatan yang dapat dilakukan wisatawan pada waktu tertentu. Kegiatan ini dilaksanakan di ruang audiovisual, bentuknya berupa penayangan film dokumenter atau film pendek bertema sosial.

\section{B. Gambaran Upaya NuArt Sculpture Park Sebagai Daya Tarik Wisata Unggulan di Kota Bandung}

\section{Analisis SWOT}

Setelah melakukan analisis dari daya tarik wisata di NuArt Sculpture Park, maka dihasilkan faktor-faktor yang menjadi strength (kekuatan), weakness (kelemahan), opportunity (peluang) dan threat (ancaman) bagi NuArt Sculpture Park dengan cara menyusun faktor-faktor strategis internal dan eksternal, sebagai berikut:

Tabel 2. Analisis SWOT Faktor Internal

\begin{tabular}{|l|c|c|c|}
\hline \multicolumn{1}{|c|}{ Uraian } & Bobot & Rating & Skor \\
\hline Strengths (Kekuatan) & \multicolumn{4}{|l|}{} \\
\hline 1. Pemilik NuArt seniman & 0.75 & 4 & 3 \\
\hline
\end{tabular}




\begin{tabular}{|l|c|c|c|}
\hline terkenal & \multicolumn{2}{|l|}{} & 4 \\
\hline $\begin{array}{l}\text { 1. NuArt memiliki keunikan } \\
\text { koleksi }\end{array}$ & 1 & 4 & 5 \\
\hline $\begin{array}{l}\text { 2. NuArt memiliki kelengkapan } \\
\text { fasilitas pariwisata }\end{array}$ & 1 & 5 & 3 \\
\hline $\begin{array}{l}\text { 3. Aktivitas yang tersedia di } \\
\text { NuArt beragam }\end{array}$ & 0.75 & 4 & 3 \\
\hline $\begin{array}{l}\text { 4. Nuart memiliki suasana yang } \\
\text { ramah lingkungan }\end{array}$ & 0.75 & 4 & $\mathbf{1 8}$ \\
\hline Jumlah & $\mathbf{4 . 2 5}$ & $\mathbf{2 1}$ & 0.5 \\
\hline Weaknesses (Kelemahan) & 0.25 & 2 & 0.75 \\
\hline $\begin{array}{l}\text { 1. Tidak tersedia angkutan umum } \\
\text { yang melintas }\end{array}$ & 0.75 & 1 & 1.5 \\
\hline $\begin{array}{l}\text { 2. Kurangnya papan petunjuk } \\
\text { lokasi }\end{array}$ & 0.5 & 3 & 1.5 \\
\hline $\begin{array}{l}\text { 3. Sumber daya manusia yang } \\
\text { masih kurang }\end{array}$ & 0.75 & 2 & 1.5 \\
\hline $\begin{array}{l}\text { 4. Promosi yang masih kurang } \\
\text { kepada masyarakat }\end{array}$ & 0.5 & 3 & $\mathbf{5 , 7 5}$ \\
\hline 5. Tidak ada event rutin & $\mathbf{2 , 7 5}$ & $\mathbf{1 1}$ & $\mathbf{3 3}$ \\
\hline Jumlah & Jumlah (S+W) & & \\
\hline
\end{tabular}

Tabel 3. Analisis SWOT Faktor Eksternal

\begin{tabular}{l|c|c|c|}
\hline \multicolumn{1}{c|}{ Uraian } & Bobot & Rating & Skor \\
\hline $\begin{array}{l}\text { Opportunities (Peluang) } \\
\begin{array}{l}\text { 1. NuArt sebagai daya tarik } \\
\text { wisata budaya unggulan di } \\
\text { Kota Bandung }\end{array}\end{array}$ & 1 & 5 & 5 \\
\hline $\begin{array}{l}\text { 2. Kunjungan wisatawan } \\
\text { meningkat }\end{array}$ & 0.75 & 4 & 3 \\
\hline Jumlah & $\mathbf{1 . 7 5}$ & $\mathbf{9}$ & $\mathbf{8}$ \\
\hline Threats (Ancaman) & 0.5 & 3 & 1.5 \\
\hline $\begin{array}{l}\text { 1. Banyak destinasi wisata yang } \\
\text { lokasinya lebih strategis }\end{array}$ & 0.75 & 3 & 2.25 \\
\hline $\begin{array}{l}\text { 2. Destinasi wisata lain } \\
\text { melakukan promosi secara } \\
\text { gencar }\end{array}$ & 0.75 & 3 & 2.25 \\
\hline 3. Kondisi Ekonomi yang buruk & $\mathbf{2}$ & $\mathbf{9}$ & $\mathbf{6}$ \\
\hline Jumlah Jumlah (O+T) & $\mathbf{3 , 7 5}$ & $\mathbf{1 8}$ & $\mathbf{1 4}$ \\
\hline \begin{tabular}{l} 
Jum \\
\hline
\end{tabular} & \multicolumn{1}{|l|}{} \\
\hline
\end{tabular}


Bobot dan rating pada tabel diatas dihasilkan dari hasil analisa penulis melalui observasi, wawancara, dan studi dokumentasi, sehingga dihasilkan bahwa faktor internal yaitu NuArt memiliki keunikan koleksi, dan kelengkapan fasilitas pariwisata merupakan faktor yang sangat penting, sementara untuk faktor eksternal yang paling penting adalah dari peluang NuArt yang dapat menjadi daya tarik wisata budaya unggulan di Kota Bandung. Karena dilihat dari hasil analisis terhadap unsur daya tarik wisata unggulan dari konsep RIPARPROV antara lain atraksi, aksesibilitas, amenitas, masyarakat, dan aktivitas, NuArt sudah memiliki kelima unsur tersebut dengan penilaian yang baik, sehingga terdapat peluang bagi NuArt untuk menjadi daya tarik wisata unggulan di Kota Bandung.

Selanjutnya dirumuskan strategi SWOT berdasarkan faktor internal dan faktor eksternal NuArt Sculpture Park dengan membuat tabel pendekatan matriks SWOT pada tabel 4. sebagai berikut:

Tabel 4. Pendekatan Matriks SWOT

\begin{tabular}{|c|c|c|}
\hline $\begin{array}{l}\text { Faktor } \\
\text { Eksternal }\end{array}$ & $\begin{array}{l}\text { Kekuatan (S) } \\
\text { 1. NuArt merupakan destinasi } \\
\text { wisata yang dimiliki oleh } \\
\text { seniman Nyoman Nuarta yang } \\
\text { sudah terkenal } \\
\text { 2. NuArt memiliki keunikan } \\
\text { Koleksi } \\
\text { 3. NuArt memiliki kelengkapan } \\
\text { fasilitas pariwisata } \\
\text { 4. Terdapat banyak aktivitas } \\
\text { menarik yang dapat } \\
\text { memberikan edukasi bagi } \\
\text { Wisatawan } \\
\text { 5. Nuart memiliki suasana yang } \\
\text { ramah lingkungan }\end{array}$ & $\begin{array}{l}\text { Kelemahan (W) } \\
\text { 1. Tidak tersedia } \\
\text { angkutan umum yang } \\
\text { melintas } \\
\text { 2. Kurangnya papan } \\
\text { petunjuk arah lokasi } \\
\text { NuArt } \\
\text { 3. Tidak ada event rutin } \\
\text { 4. Sumber daya manusia } \\
\text { yang masih kurang } \\
\text { 5. Promosi yang masih } \\
\text { kurang kepada } \\
\text { masyarakat }\end{array}$ \\
\hline $\begin{array}{l}\text { Peluang }(\mathbf{O}) \\
\text { 1. NuArt } \\
\text { sebagai } \\
\text { daya tarik } \\
\text { wisata } \\
\text { budaya } \\
\text { unggulan } \\
\text { di Kota } \\
\text { Bandung } \\
\text { 2. Kunjunga }\end{array}$ & $\begin{array}{l}\text { Strategi SO } \\
\text { 1. Memperbanyak koleksi karya } \\
\text { patung Nyoman Nuarta } \\
\text { 2. Memberikan petunjuk arah } \\
\text { untuk mempermudah } \\
\text { wisatawan mengetahui letak } \\
\text { fasilitas yang terdapat di } \\
\text { NuArt } \\
\text { 3. Meningkatkan kebersihan dan } \\
\text { kenyamanan di NuArt seperti }\end{array}$ & $\begin{array}{l}\text { Strategi WO } \\
\text { 1. Menambah pegawai } \\
\text { profesional yang } \\
\text { sesuai dengan } \\
\text { bidangnya } \\
\text { 2. Merancang program } \\
\text { event rutin }\end{array}$ \\
\hline
\end{tabular}




\begin{tabular}{|c|c|c|}
\hline $\begin{array}{r}\text { 2. Kunjungan } \\
\text { wisatawan } \\
\text { meningkat }\end{array}$ & $\begin{array}{l}\text { tidak membuang sampah } \\
\text { sembarangan dan merawat } \\
\text { tanaman dengan } \\
\text { menyiraminya setiap hari } \\
\text { 4. Menginformasikan kepada } \\
\text { wisatawan mengenai program } \\
\text { kegiatan yang diselenggarakan } \\
\text { di NuArt }\end{array}$ & \\
\hline \begin{tabular}{|l} 
Ancaman (T) \\
1. \\
Banyak \\
destinasi \\
wisata \\
yang \\
lokasinya \\
lebih \\
strategis \\
2. Destinasi \\
wisata \\
lain yang \\
melakuka \\
n promosi \\
lebih \\
gencar \\
3. Kondisi \\
ekonomi \\
yang \\
buruk
\end{tabular} & $\begin{array}{l}\text { Strategi ST } \\
\text { 1. Mengemas paket kunjungan } \\
\text { wisata yang menarik untuk } \\
\text { Wisatawan } \\
\text { 2. Menjalin kerjasama dengan } \\
\text { pemerintah kota } \\
\text { 3. Menjalin kerjasama dengan } \\
\text { biro perjalanan wisata }\end{array}$ & $\begin{array}{l}\text { Strategi WT } \\
\text { 1. Membuat papan } \\
\text { petunjuk arah di } \\
\text { beberapa lokasi } \\
\text { jalan raya umum } \\
\text { 2. Melakukan } \\
\text { pemasaran secara } \\
\text { maksimal melalui } \\
\text { berbagai media } \\
\text { cetak dan } \\
\text { elektronik. }\end{array}$ \\
\hline \multicolumn{3}{|c|}{ Sumber: Pengolahan Data Penelitian } \\
\hline
\end{tabular}

Berdasarkan tabel 4 dapat disimpulkan bahwa, jika NuArt ingin dikembangkan menjadi wisata budaya unggulan perlu diambil strategi-strategi sebagai berikut:

1. Memperbanyak koleksi karya patung Nyoman Nuarta

2. Memberikan petunjuk arah untuk mempermudah wisatawan mengetahui letak fasilitas yang terdapat di NuArt

3. Meningkatkan kebersihan dan kenyamanan di NuArt seperti tidak membuang sampah sembarangan dan merawat tanaman dengan menyiraminya setiap hari

4. Menginformasikan kepada wisatawan mengenai program kegiatan yang diselenggarakan di NuArt

5. Menambah pegawai profesional yang sesuai dengan bidangnya

6. Merancang program event rutin

7. Mengemas paket kunjungan wisata yang menarik untuk wisatawan

8. Menjalin kerjasama dengan pemerintah kota

9. Menjalin kerjasama dengan biro perjalanan wisata

10. Mengemas paket kunjungan wisata yang menarik untuk wisatawan 
11. Menjalin kerjasama dengan pemerintah kota

12. Menjalin kerjasama dengan biro perjalanan wisata mengemas paket kunjungan wisata yang menarik untuk wisatawan

13. Menjalin kerjasama dengan pemerintah kota

14. Menjalin kerjasama dengan biro perjalanan wisata

15. Membuat papan petunjuk arah di beberapa lokasi jalan raya umum

16. Melakukan pemasaran secara maksimal melalui berbagai media cetak dan elektronik.

\section{SIMPULAN}

1. Dari hasil analisis terhadap potensi dan daya tarik di NuArt Sculpture Park terdiri dari:

a. Atraksi berupa patung-patung hasil karya Nyoman Nuarta yang memiliki keunikan bentuk dan bahan dasar Selain itu terdapat event yang rencananya akan rutin diselenggara-kan di NuArt.

b. Aksesibilitas menuju NuArt Sculpture Park sangat baik karena terdapat jalan raya yang memadai untuk mencapai lokasi, namun informasi mengenai papan petunjuk di jalan raya umum yang menunjukan lokasi NuArt belum tersedia, dan tidak tersedia transportasi umum.

c. Amenitas yang tersedia di NuArt Sculpture Park cukup lengkap mulai dari toilet dan musholla hingga fasilitas ruang pertunjukan berupa galeri, taman patung, ruang pertemuan, area workshop, restoran dan coffe shop, dan ruang auditorium. Fasilitas penginapan bagi wisatawan belum tersedia, dan rencana kedepan NuArt akan membangun penginapan berupa cottage.

d. Masyarakat sekitar yang memenuhi konsep sadar wisata diantaranya unsur aman, tertib, bersih, sejuk, indah, ramah, dan kenangan sudah tersedia dengan baik

e. Aktivitas yang beragam ditawarkan bagi wisatawan antara lain, jalan-jalan di kawasan mulai dari galeri, taman patung hingga area workshop, short course, craft corner, art performance, dan menyaksikan film pendek.

2. NuArt Sculpture Park dapat dijadikan wisata budaya unggulan di kota Bandung, karena dari hasil penelitian menunjukan $\mathrm{Nu}$ Art bahwa faktor internal yaitu NuArt memiliki keunikan koleksi, dan kelengkapan fasilitas pariwisata merupakan faktor yang sangat penting, sementara untuk faktor eksternal yang paling penting adalah dari peluang NuArt yang dapat menjadi daya tarik wisata budaya unggulan di Kota Bandung. Karena dilihat dari hasil analisis terhadap unsur daya tarik wisata unggulan dari konsep RIPARPROV antara lain atraksi, aksesibilitas, amenitas, masyarakat, dan aktivitas, NuArt sudah memiliki kelima unsur tersebut dengan penilaian yang baik, sehingga terdapat peluang bagi NuArt untuk menjadi daya tarik wisata unggulan didi Kota Bandung memenuhi syaratsyarat internal dan dan eksternal. 
Bahwa dilihat dari faktor internal NuArt memiliki keunikan koleksi, dan kelengkapan fasilitas pariwisata merupakan faktor yang sangat penting, sementara untuk faktor eksternal yang paling penting adalah dari peluang NuArt yang dapat menjadi daya tarik wisata budaya unggulan di Kota Bandung. Karena dilihat dari hasil analisis terhadap unsur daya tarik wisata unggulan dari konsep RIPARPROV antara lain atraksi, aksesibilitas, amenitas, masyarakat, dan aktivitas, NuArt sudah memiliki kelima unsur tersebut dengan penilaian yang baik, sehingga terdapat peluang bagi NuArt untuk menjadi daya tarik wisata unggulan di Kota Bandung.

\section{SARAN}

Adapun saran yang dapat diambil dari hasil temuan penelitian di lapangan antara lain:

1. Potensi dan daya tarik di NuArt Sculpture Park perlu ditingkatkan ditinjau dari unsur berikut:

a. Atraksi, dengan melakukan penambahan koleksi patung, karena masih terdapat ruang kosong di bagian dalam galeri, menyelenggarakan event rutin sebagai bagian dari atraksi dan juga sebagai cara untuk meningkatkan promosi.

b. Aksesibilitas, dengan menambahkan papan petunjuk arah di jalan raya umum, dan juga papan petunjuk informasi mengenai fasilitas di kawasan NuArt.

c. Amenitas, dengan membuat penginapan sederhana karena lokasi NuArt yang berada dalam area perumahan dan tidak terdapat hotel serta penginapan di sekitar kawasan.

2. Upaya yang dapat diambil perusahaan untuk strategi ke depan agar menjadikan NuArt sebagai daya tarik wisata unggulan budaya di Kota Bandung berdasarkan analisis SWOT antara lain meningkatkan promosi yang lebih gencar terutama di media internet karena suasana di NuArt masih sepi, selain itu juga NuArt perlu menjalin kerjasama dengan pemerintah kota Bandung dan biro perjalanan wisata.

\section{DAFTAR PUSTAKA}

Ismayanti. 2010. Pengantar Pariwisata. Jakarta : Grasindo

Moleong, Lexy J. (2012). Metodologi Penelitian Kualitatif. Bandung: PT Remaja Rosdakarya

Sangadji, Etta Mamang dan Sopiah. (2010). Metodologi Penelitian - Pendekatan

Praktis dalam Penelitian. Yogyakarta: Andi

Suwantoro, Gamal. 2004. Dasar-Dasar Pariwisata. Yogyakarta : Andi

Utama, I Gusti Bagus Rai dan Mahadewi. (2012). Metodologi Penelitian

Pariwisata dan Perhotelan. Yogyakarta: Andi 
Volume 2 Nomor 1 Desember 2016

Tourism Scientific Journal

Volume 2 Nomor 1 Desember 2016

\section{Peraturan Daerah:}

RIPARPROV. (2015). Rencana Induk Pembangunan Kepariwisataan Provinsi. Bandung: DISPARBUD JABAR

Undang-Undang No. 10 Tahun 2009. Kepariwisataan. Jakarta: Departemen Pariwisata Budaya Republik Indonesia 